\title{
Reinforcing effects of methamphetamine in an animal model of Attention-Deficit/Hyperactivity Disorder-the Spontaneously Hypertensive Rat
}

\author{
Ike dela Peña ${ }^{1}$, Hyung Seok Ahn ${ }^{1}$, Ji Young Choi ${ }^{1}$, Chan Young Shin², Jong Hoon Ryu ${ }^{3}$, Jae Hoon Cheong ${ }^{1 *}$
}

\begin{abstract}
Substrains of the Spontaneously Hypertensive rat (SHR), a putative animal model of Attention-Deficit/Hyperactivity Disorder (ADHD), have demonstrated increased sensitivity to many drugs of abuse, including psychostimulants. Therefore, it was suggested that studies in SHR may help elucidate ADHD and comorbidity with substance use disorder (SUD). However, the drug intake profile of the SHR in the most relevant animal model of drug addiction, the self-administration (SA) test, and its response on the conditioned place preference (CPP) paradigm are not yet determined. In the present study, we employed SA and CPP tests to investigate the reinforcing effects of the psychostimulant methamphetamine in an SHR substrain obtained from Charles River, Japan (SHR/NCrlCrlj). Concurrent tests were also performed in Wistar rats, the strain representing "normal" heterogeneous population. To address if the presence of ADHD behaviors further increases sensitivity to the rewarding effect of methamphetamine during adolescence, a critical period for the onset of drug abuse, CPP tests were especially conducted in adolescent Wistar and SHR/NCrlCrlj. We found that the SHR/NCrlCrlj also acquired methamphetamine SA and CPP, indicating reinforcing effects of methamphetamine in this ADHD animal model. However, we did not observe increased responsiveness of the SHR/NCrlCrlj to methamphetamine in both SA and CPP assays. This indicates that the reinforcing effects of methamphetamine may be similar in strains and that the SHR/NCrlCrlj may not adequately model ADHD and increased sensitivity to methamphetamine.
\end{abstract}

\section{Findings}

Attention-Deficit/Hyperactivity Disorder (ADHD) is a complex neurodevelopmental disorder characterized by the core symptoms such as hyperactivity, inattention and impulsivity $[1,2]$. It is the most commonly diagnosed disorder of childhood [3] and also present in about $4 \%-9 \%$ of youths [4,5] and $4 \%$ of adults [6]. ADHD is comorbid with substance use disorder (SUD) $[7,8]$ and epidemiological data not only affirm the ADHD-SUD link but also indicate greater risk for earlier onset of substance abuse among ADHD individuals [4,9-11]. The exact etiology, however, cannot be determined for in some respects, there is a lack of appropriate animal models [12].

The Spontaneously Hypertensive rat (SHR), bred from the normotensive Wistar Kyoto (WKY) rat strain, is the

\footnotetext{
* Correspondence: cheongjh@syu.ac.kr

'Uimyung Research Institute for Neuroscience, Sahmyook University, 26-21

Kongkreung-dong, Nowon-gu Seoul 139-742, Korea

Full list of author information is available at the end of the article
}

most validated animal model of ADHD [13]. A number of SHR substrains exist [14] and Sagvolden et al [15] asserted that the SHR obtained from Charles River, Germany (SHR/NCrl), with the WKY bred from Harlan, UK (WKY/NHsd) as the reference strain, most excellently represents ADHD. Nevertheless, earlier studies have found increased reactivity of some SHR substrains (e.g. SHR/NTac, SHR/NCrl) to stimulants, opioids, alcohol and other addictive drugs in comparison with other rat strains [see [12] for review], indicating that the SHR, in general, may be used to investigate the relationship between ADHD and drug addiction. However, the behavioral profiles of the SHR in the most relevant drug addiction assay, the self-administration (SA) paradigm [12] and in another animal model of addiction, the conditioned place preference (CPP) protocol [16] are not completely known.

In this study, we conducted SA and CPP tests in an SHR substrain obtained from Charles River, Japan (SHR/NCrlCrlj) (via Orient Bio., Korea), to investigate if

\section{Ciomed Central}


it shows stable responding for the stimulant methamphetamine. Its response was compared with the Wistar rat, strain representing the "normal" heterogeneous population [17-19]. Adolescence is a risk factor for addiction [20] and it is known that children with ADHD are more vulnerable to use illicit drugs than children without it $[21,22]$. We would like to know if we can model this in our study, thus CPP tests were conducted in adolescent Wistar and SHR/NCrlCrlj.

All experiments complied with the Principles of Laboratory Animal Care (NIH) and the Animal Care and Use Guidelines of Sahmyook University, Korea. We used adolescent (PND 20-47) and adult (PND 90-110) male outbred Wistar and inbred SHR/NCrlCrlj. They were housed collectively ( 8 rats/cage in CPP experiments) or individually (SA experiments), in a temperature $\left(22 \pm 2^{\circ} \mathrm{C}\right)$ and humidity- $(55 \pm 5 \%)$ controlled animal room with a $12 \mathrm{hr} / 12 \mathrm{hr}$ light/dark (6 AM-6 PM) cycle. They had free food and water access except during tests and on initial lever-training sessions (SA test). Methamphetamine hydrochloride, procured from Korea Food and Drug Administration, was dissolved in saline for use in all experiments.

Self-administration tests were carried out in standard operant chambers (Coulbourn Instruments, Allentown, PA, USA) and the methods employed were as outlined previously [23]. Briefly, after rats acquired stable lever responding, they were implanted with silastic catheters in the right jugular vein. SA tests commenced after they have recovered from surgery. Two levers were present during SA tests and response on the left lever (active lever, FR1) switched on the infusion pump for $10 \mathrm{~s}$, delivering $0.1 \mathrm{ml}$ of $0.25 \mathrm{mg}$ methamphetamine, and also the stimulus light above it (which was lit for $10 \mathrm{~s}$ and $20 \mathrm{~s}$ more after the end of the infusion). A timeout period was indicated and no priming injections were given at any time. Rats were only allowed up to 30 infusions although lever responses were recorded until the end of the 2-hour SA. Catheter patency was ensured as detailed [23].

Conditioned place preference tests were conducted in two-compartment polyvinylchloride boxes having distinct visual and tactile cues. The methods were patterned after previous reports [23,24] with some modifications. After determining the rats' initially-preferred compartment, approximately half of the rats per group were assigned to the black compartment as the drug-paired side, while the other half to the other [24]. If their staying time was less than $200 \mathrm{~s}$, they were excluded from further testing. Conditioning phase followed where animals were paired with methamphetamine $(1.25$ or $5 \mathrm{mg} / \mathrm{kg})$ or saline in their non-preferred

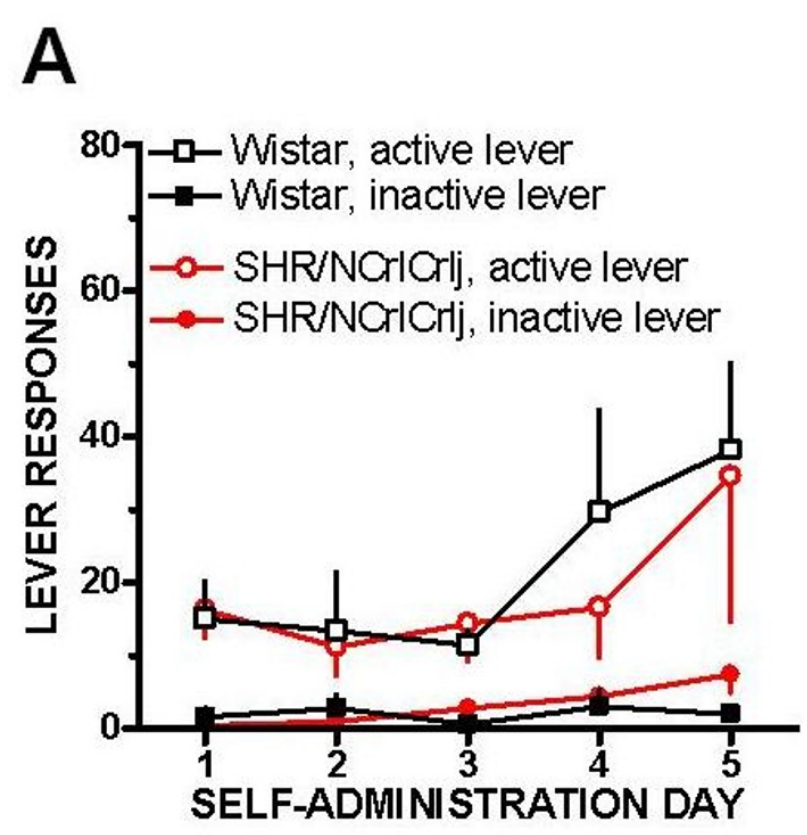

B

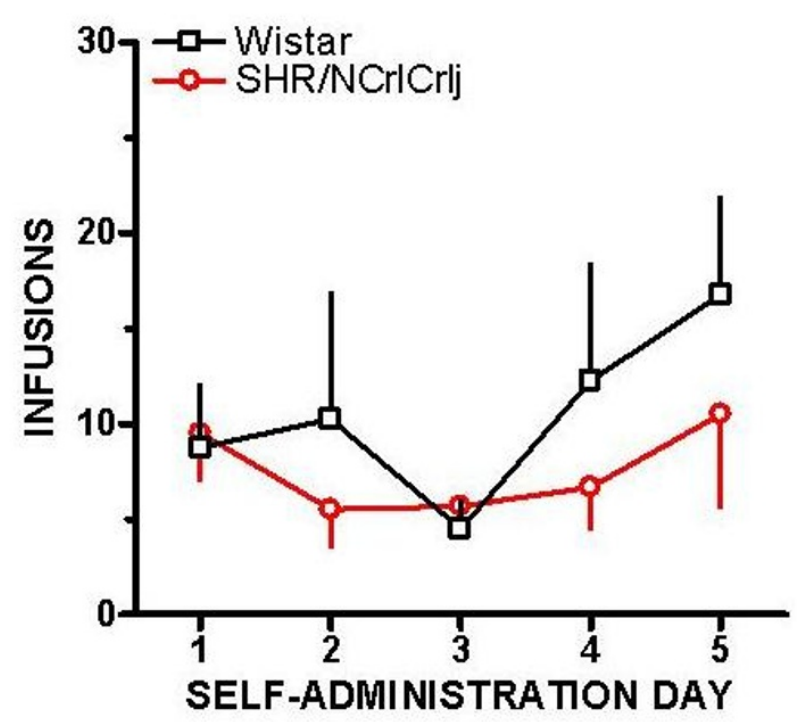

Figure 1 Acquisition of methamphetamine self-administration (SA). (A) Mean total number of lever responses of Wistar rats and SHR/ $\mathrm{NCrlCrlj}$ during the 2-hour methamphetamine SA. Open symbols indicate lever responses on the active (reinforced) lever and filled symbols show responses for the inactive (non-reinforced) lever. (B) Mean infusions obtained by Wistar and SHR/NCrlCrlj during the 2-hour methamphetamine self-administration. Empty squares are responses of Wistar rats and circles are for SHR/NCrlCrlj. Data are presented as means $\pm \operatorname{SEM}(n=6)$. 
compartment. The rest of the procedures were performed as described [23]. Post- and preconditioning staying times were determined using automated systems (Ethovision Noldus IT b.v., Netherlands).

Two-way ANOVA was used to determine the effects of strains or days or interaction between these factors in SA tests (active $v s$ inactive lever presses, and total number of methamphetamine infusions) and also in CPP tests (strains or treatment effects and interaction between them). Student's $t$-test was used for further analysis. The significance level was set to $\mathrm{p}<0.05$.

Figure 1A shows that both strains acquired methamphetamine SA. Responses for the active $v s$ inactive lever differed significantly in Wistar $(\mathrm{F}(1,50)=59.92, \mathrm{p}<$ $0.001)$ and in SHR/NCrlCrlj $(\mathrm{F}(1,50)=42.26, \mathrm{p}<$ $0.001)$. However, two-way ANOVA only revealed significant effect of days $(\mathrm{F}(4,50)=5.69, \mathrm{p}<0.001)$, but without any strain $\times$ days interaction. In Figure $1 \mathrm{~B}$, the number of methamphetamine infusions earned by SHR/
$\mathrm{NCrlCrlj}$ and Wistar rats during the SA tests is shown. Significant days $(\mathrm{F}(4,50)=7.01, \mathrm{p}<0.001)$ but not strain effects was noted, and there was no strain $\mathrm{x}$ days interaction.

Figure 2 illustrates that CPP was expressed by both strains in response to methamphetamine conditioning. There was a remarkable effect of treatment $(F(2,42)=$ $6.46, \mathrm{p}<0.05)$, but no strain effects, and strain $\times$ treatment interaction. In Wistar rats, there was CPP to $1.25 \mathrm{mg} / \mathrm{kg}(\mathrm{t}(14)=1.81, \mathrm{p}<0.05)$ and $5 \mathrm{mg} / \mathrm{kg}$ $(\mathrm{t}(14)=2.17, \mathrm{p}<0.05)$ methamphetamine. CPP was also demonstrated by SHR/NCrlCrlj conditioned with $1.25(\mathrm{t}(14)=3.33, \mathrm{p}<0.01)$ and $5 \mathrm{mg} / \mathrm{kg}(\mathrm{t}(14)=2.96$, $\mathrm{p}<0.01)$ methamphetamine.

This study showed that the SHR/NCrlCrlj, alike the Wistar rat, readily acquired methamphetamine selfadministration. Adolescent SHR/NCrlCrlj also demonstrated conditioned place preference to methamphetamine although in both assays differential strain response

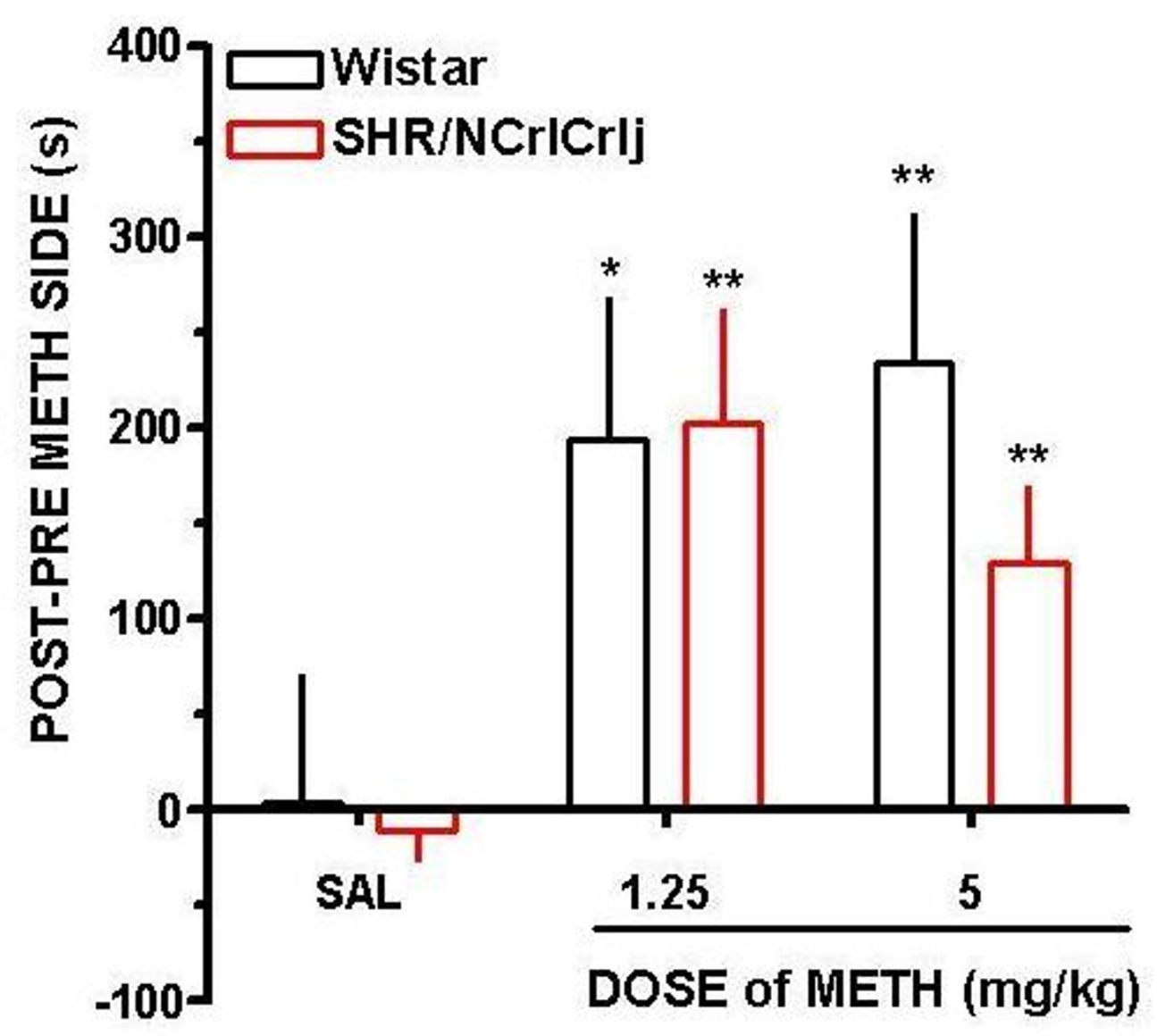

Figure 2 Rewarding effects of methamphetamine (METH) in Wistar and SHR/NCrICrlj. (A) Place preference data (mean \pm SEM) expressed as the difference in the amount of time spent in the METH-paired compartment during the post- and preconditioning days. Data are expressed as mean \pm SEM. ${ }^{*} p<0.05,{ }^{* *} p<0.01$ when comparing saline (SAL) vs METH-conditioned animals $(n=8)$. 
was not observed. It indicates that the reinforcing/ rewarding properties of methamphetamine are similar in both strains and more importantly, that the SHR/ $\mathrm{NCrlCrlj}$ may not be more sensitive to methamphetamine reward/reinforcement. The results herein do not conform to previous investigations. Initially, it has been predicted that the SHR would show increased behavioral response to addictive drugs not only for their ADHDlike behaviors, but also as it manifests high levels of impulsivity, novelty-seeking behaviors [25] and defective/deficient reinforcement processes [26]. These behaviors predispose greater vulnerability to drug abuse as known in human studies $[27,28]$. Secondly, our results do not coincide with previous studies (which used locomotor activity as an index to the reinforcing effects of drugs) which demonstrated increased behavioral response of an SHR substrain (SHR/NTac) to amphetamine, methylphenidate and the selective D1 receptor agonist SKF-81297, as compared to Wistar Kyoto rats (WKY/NTac) [29-32]. However, one study has found similarity of the effects of amphetamine or GBR-12909, a dopamine reuptake inhibitor, in another SHR substrain (SHR/Cbp) and in WKY/Cbp [33]. The present inconsistency could be due to the following factors: (1) difference in procedures (i.e. locomotor activity and SA tests measure different aspects of reinforcement mechanism) and (2) difference in SHR substrains used (i.e. the SHR substrain used herein may deviate phenotypically or genetically from SHR/NCrl bred in the USA or elsewhere) [15]. Nevertheless, it has to be considered that stimulants act differently in exerting their reinforcing effects [34]. This factor may also have influenced the present results. At any rate, additional investigations should be performed to resolve this discrepancy.

Our CPP results do not model increased vulnerability of ADHD children to drugs of abuse in comparison with "normal" children $[21,22]$. However, our data may represent a previous study which showed no difference in the rates of drug abuse or dependence to individual substances in both ADHD and non-ADHD controls [35]. Of interest is that our CPP data agree with those obtained in SA test. This is notable considering that $\mathrm{CPP}$ and SA are believed to be dissimilar forms of drug reward [36-38].

In summary, we have shown that the SHR/NCrlCrlj also shows stable responding and CPP to methamphetamine. However, we have not observed increased sensitivity of this substrain to methamphetamine reward/ reinforcement relative to Wistar rats, showing that it may not fully represent ADHD and increased vulnerability to methamphetamine. Concerning methamphetamine-induced CPP in SHR/NCrlCrlj, it cannot be attributed to an anxiolytic effect of repeated methamphetamine treatment [see [39]], as drug-induced anxiolysis (which may influence place preference) is not always apparent with drug-induced decreases in central serotonin [40]. It could not be due to "response to novelty" [36] as the CPP procedure was modified to minimize the effect of this confound. In future studies, it would be worthwhile to compare the behavioral responses of the SHR/NCrlCrlj or SHR/NCrl (of Charles River, Germany) with its most appropriate control strain, the WKY/NHsd, in both SA and CPP assays. Such work may not only determine the reliability of the present conclusion, but may also give clues on the contribution of neurobiological differences (seen in ADHD and non-ADHD individuals) in response to the reinforcing effects of drugs of abuse.

\section{Acknowledgements}

This research was funded by grants from the Korean Food and Drug Administration (09172- \%\%\% 671) and Sahmyook University.

\section{Author details}

${ }^{1}$ Uimyung Research Institute for Neuroscience, Sahmyook University, 26-21 Kongkreung-dong, Nowon-gu Seoul 139-742, Korea. ${ }^{2}$ Center for Geriatric Neuroscience Research, Institute of Biomedical Science and Technology, Konkuk University, Seoul, 143-701 Korea. ${ }^{3}$ Department of Oriental

Pharmaceutical Science, Kyunghee University, Dongdaemun-gu, Hoegidong, Seoul 130-701, Korea.

\section{Authors' contributions}

ID and JHC conceived and designed the study. ID, HSA and JYC performed the SA and CPP experiments. ID performed the statistical analysis while SCY, JHR JHC provided insights on interpreting the results. All authors

participated in drafting and in writing the final version of the manuscript.

\section{Competing interests}

The authors declare that they have no competing interests.

Received: 16 August 2010 Accepted: 9 December 2010

Published: 9 December 2010

\section{References}

1. Taylor E: Clinical foundations of hyperactivity research. Behav Brain Res 1998, 94:11-24.

2. Himelstein J, Newcorn JH, Halperin JM: The neurobiology of attentiondeficit hyperactivity disorder. Front Biosci 2000, 5:461-478.

3. Swanson J, McBurnett K, Christian D, Wigal T: Stimulant medications and the treatment of children with ADHD. In Advances in Clinical Psychology. Edited by: Ollendick T, Prinz R. New York, NY: Plenum Press; 1995:265-322.

4. Anderson JC, Williams S, McGee R, Silva PA: DSM-III disorders in preadolescent children. Prevalence in a large sample from the general population. Arch Gen Psychiatry 1987, 44:69-76.

5. Bird HR, Gould MS, Staghezza BM: Patterns of psychiatric comorbidity in a community sample of children aged 9 through 16 years. J Am Acad Child Adolesc Psychiatry 1993, 32:361-368.

6. Kessler RC, Adler L, Barkley R, Biederman J, Conners CK, Demler O, Faraone SV, Greehill L, Howes MJ, Secnik K, Spencer T, Ustun TB, Walters EE, Zaslavsky AM: The prevalence and correlates of adult ADHD in the United: results from the national Comorbidity Survey Replication. Am J Psychiatry 2006, 163(4):716-23.

7. Wilens T, Spencer T: The stimulants revisited. Child Adolesc Psychiatric Clin North Am 2000, 9:573-603.

8. Gordon SM, Tulak F, Troncale J: Prevalence and characteristics of adolescents patients with co-occurring ADHD and substance dependence. J Addict Dis 2004, 23(4):31-40.

9. Ohlmeier MD, Peters K, Te Wildt BT, Zedler M, Ziegenbein M, Wiese B, Emrich HM, Schneider U: Comorbidity of alcohol and substance 
dependence with attention-deficit/hyperactivity disorder (ADHD). Alcohol Alcohol 2008, 43(3):300-4.

10. Feltenstein MW, See RE: The neurocircuitry of addiction: an overview. $\mathrm{Br} J$ Pharmacol 2008, 154(2):261-74.

11. Kohnke MD: Approach to the genetics of alcoholism: a review based on pathophysiology. Biochem Pharmacol 2008, 75(1):160-77.

12. Vendruscolo LF, Izidio GS, Takahashi RN: Drug reinforcement in a rat model of attention deficit/hyperactivity disorder- the spontaneously hypertensive rat (SHR). Curr Drug Abuse Rev 2009, 2:177-183.

13. Sagvolden T, Russell VA, Aase $H$, Johansen EB, Farshbaf M: Rodent models of attention-deficit/hyperactivity disorder. Biol Psychiatry 2005, 57(11):1239-47.

14. Rat Genome Database. 2008 [http://rgd.mcw.edu].

15. Sagvolden T, Johansen EB, Wøien G, Walaas SI, Storm-Mathisen J, Bergersen LH, Hvalby O, Jensen V, Aase H, Russell VA, Killeen PR, Dasbanerjee T, Middleton FA, Faraone SV: The spontaneously hypertensive rat model of ADHD-the importance of selecting the appropriate reference strain. Neuropharmacol 2009, 57(7-8):619-26.

16. Tzschentke TM: Measuring reward with the conditioned place preference (CPP) paradigm: update of the last decade. Addict Biol 2007, 12:227-462

17. Pamplona FA, Vendruscolo LF, Takahashi RN: Increased sensitivity to cocaine-induced analgesia in Spontaneously Hypertensive rats (SHR). Behav Brain Funct 2007, 3:9.

18. Pandolfo P, Pamplona F, Prediger R, Takahashi R: Increased sensitivity of adolescent spontaneously hypertensive rats, an animal model of attention deficit hyperactivity disorder, to the locomotor stimulation induced by cannabinoid receptor agonist WIN 55,212-2. Eur J Pharmacol 2007, 563:141-148

19. Pandolfo P, Vendruscolo L, Sordi R, Takahashi R: Cannabinoid-induced conditioned place preference in the spontaneously hypertensive rat-an animal model of attention deficit hyperactivity disorder. Psychopharmacol 2009, 205:319-326

20. Chambers R, Taylor JR, Potenza MN: Developmental neurocircuitry of motivation in adolescence: a critical period of addiction vulnerability Am J Psychiatry 2003, 160:1041-1052.

21. Sullivan MA, Rudnik-Levin F: Attention deficit/hyperactivity and substance abuse. Diagnostic and therapeutic considerations. Ann NY Acad Sci 2001, 931:251-270.

22. Schubiner $\mathrm{H}$ : Substance abuse in patients with attention-deficit hyperactivity disorder: therapeutic implications. CNS Drugs 2005, 19:643-655.

23. dela Pena IC, Ahn HS, Choi JY, Shin CY, Ryu JH, Cheong JH: Methylphenidate self-administration and conditioned place preference in an animal model of attention deficit hyperactivity disorder-the spontaneously hypertensive rat. Behav Pharmacol.

24. Merirrine E, Kankaanpaa A, Seppala T: Rewarding properties of methylphenidate: sensitization by prior exposure to the drug and effects of dopamine D1- and D2- receptor antagonists. J Phamacol Exp Ther 2001, 298:539-550.

25. Da Silva GE, Vendruscolo LF, Takahashi RN: Effects of ethanol on locomotor and anxiety-like behaviors and the acquisition of ethanol intake in Lewis and spontaneously hypertensive rats. Life Sci 2005, 77(6):693-706.

26. Blum K, Braverman E, Comings D, Chen T, Arcuri V, Blum S, Downs B, Waite R, Notaro A, Lubar J, Williams L, Prihoda T, Palomo T, Oscarberman M: Attention-deficit-hyperactivity disorder and reward deficiency syndrome. Neuropsychiatr Dis Treat 2008, 4(5):893-917.

27. Clure C, Brady K, Saladin M, Johnson D, Waid R, Rittenbury M: Attentiondeficit/hyperactivity disorder and substance use: symptom pattern and drug choice. Am J Drug Alcohol Abuse 1999, 25(3):441-448.

28. Jaffe C, Bush KR, Straits-Troster K, Meredith C, Romwall L, Rosenbaum G, Cherrier M, Saxon AJ: A comparison of methamphetamine-dependent inpatients childhood attention deficit hyperactivity disorder symptomatology. J Addict Dis 2005, 24(3):133-52.

29. Yang PB, Amini B, Swann AC, Dafny N: Strain differences in the behavioral responses of male rats to chronically administered methylphenidate. Brain Res 2003, 971(2):139-52.

30. Amini B, Yang PB, Swann AC, Dafny N: Differential locomotor responses in male rats from three strains to acute methylphenidate. Int J Neurosci 2004, 114(9):1063-83.
31. Tsai CF, Lin MT: Locomotor hyperactivity in hypertensive rats. Pharmacol 1988, 36(1):27-34.

32. Diaz Heijtz R, Castellanos FX: Differential effects of a selective dopamine D1-like receptor agonist on motor activity and c-fos expression in the frontal-striatal circuitry of SHR and Wistar-Kyoto rats. Behav Brain Funct 2006, 2:18.

33. van den Buuse $M$, de Jong W: Differential effects of dopaminergic drugs on open-field behavior of spontaneously hypertensive rats and normotensive Wistar-Kyoto rats. J Pharmacol Exp Ther 1989, 248(3):1189-96.

34. Riddle EL, Fleckenstein AE, Hanson GR: Role of monoamine transporters in mediating psychostimulant effects. AAPS J 2005, 7(4):E847-E851.

35. Biederman J, Wilens T, Mick E, Faraone SV, Weber W, Curtis S, Thornell A, Pfister K, Jetton JG, Soriano J: Is ADHD a risk factor for psychoactive substance use disorders? Findings from a four-year prospective followup study. J Am Acad Child Adol Psychiatry 1997, 36(1):21-29.

36. Bardo MT, Bevins A: Conditioned place preference:what does it add to our preclinical understanding of drug reward? Psychopharmacol 2000, 153(1):31-43.

37. Williams JS: Researchers Probe for Clues to ADHD Medications' Protective Effects. NIDA Notes 2003, 18(1):11-13.

38. Stefanski R, Ladenheim B, Lee SH, Cadet JL, Goldberg SR: Neuroadaptations in the dopaminergic system after active selfadministration but not after passive administration of methamphetamine. Eur J Pharmacol 1999, 371:123-135.

39. Iversen SD: 5-HT and anxiety. Neuropharmacol 1984, 23:1553-1560.

40. Green AR, MCGregor IS: On the anxiogenic and anxiolytic nature of longterm cerebral 5-HT depletion following MDMA. Psychopharmacol 2002, 162:448-450.

doi:10.1186/1744-9081-6-72

Cite this article as: dela Peña et al:: Reinforcing effects of methamphetamine in an animal model of Attention-Deficit/ Hyperactivity Disorder-the Spontaneously Hypertensive Rat. Behavioral and Brain Functions 2010 6:72.

\section{Submit your next manuscript to BioMed Central and take full advantage of:}

- Convenient online submission

- Thorough peer review

- No space constraints or color figure charges

- Immediate publication on acceptance

- Inclusion in PubMed, CAS, Scopus and Google Scholar

- Research which is freely available for redistribution 